\title{
Acquisition Sequences and Definition of Linguistic Categories
}

\author{
Gabriele Pallotti* and Alessandra Peloso
}

College of Education, University of Modena and Reggio Emilia, Italy

\begin{abstract}
The article provides a methodological discussion on the definition of linguistic structures in interlanguage. Data come from an Eritrean learner observed during the first months of exposure to Italian as a second language. Previous research identified some developmental sequences for the acquisition of verb morphology, but it is not always clear how metalinguistic terms used in such sequences (e.g. 'present tense', 'past participle') should be interpreted. The article discusses the issue in depth, by providing several explicit definitions for some of the structures involved in the sequence, notably present tense, person marking, past participle and present perfect. Results show that different definitions of the interlanguage structures may lead to different acquisition orders. These findings suggest that the formulation of developmental sequences should be based on clear, explicit definitions both of the acquisition criteria and of the structures investigated.
\end{abstract}

\section{INTRODUCTION}

Since the 70s, much research has been carried out on the order in which structures develop in a second language (L2). Following Cazden [1] and Brown [2], who described developmental sequences for the mother tongue, Dulay and Burt [3] showed that learners of English as a second language also acquire certain grammatical morphemes in a given order. Their results were based on a cross-sectional comparison of accuracy scores by different subjects. Subsequent studies, conducted both with longitudinal and cross-sectional data, have basically confirmed the initial results, although some methodological questions were raised, concerning for example the generalizability of results from individual trajectories to group scores, elicitation methods, acquisition criteria (for comprehensive reviews see $[4,5]$ ). These studies have been followed by others, all aiming at the identification of developmental sequences, such as those by Wode [6] and Cancino, Rosansky and Schumann [7] on negation in English, by the ZISA group [8] on German syntax, by BardoviHarlig [9] on tense and aspect in English, and Bartning and Schlyter [10] on French morphosyntax. A theory entirely devoted to explaining developmental sequences is Processability Theory (PT) [11-13], which has been applied to several languages, including English [14], Swedish [15], Chinese [16], and Italian [17, 18]. Explanations for developmental sequences have been put forward by different theoretical frameworks, such as functionalism [19] and Universal Grammar [20].

From a methodological point of view, in this type of research two key constructs must be adequately defined: 'acquisition' and the 'structures' to be acquired. Acquisition has been operationalized through a number of variously defined criteria. According to some authors, a structure is acquired when it is accurately used in $60 \%$ [21], $80 \%$ [22], or $90 \%$ [3, 23 ] of cases. From this perspective, acquisition is identified as a certain - rather high - degree of mastery. Other

*Address correspondence to this author at the College of Education, University of Modena and Reggio Emilia, Italy; E-mail: pallotti@uniss.it scholars, including Pienemann [11] (p. 137), have criticized this definition, preferring instead that of emergence. Operational definitions of emergence vary too, ranging from the presence of one single token [24] to more stringent requirements, such as a minimum number of tokens and/or lexical and morphological variability (e.g. $[12,16,25])$. Hatch and Faraday [26] have shown that different operational definitions of acquisition criteria, such as placing the accuracy threshold at 60 or $80 \%$, lead to different acquisition orders. More recently, Pallotti [25] has critically discussed the emergence construct, similarly showing that various ways of operationalizing it may lead to slight differences in acquisition sequences and emphasizing the need for explicit, reliable operational definitions based on a theoretical analysis of the constructs involved.

Similar remarks can be made regarding the issue of what exactly is acquired. Acquisitional sequences often employ grammatical categories taken from the target language, such as 'accusative', 'present tense' and 'simple past'. However, an interlanguage cannot be described entirely in terms of the target language. While it is true that learner varieties tend towards the L2, it is also true that, especially in the early stages, they are autonomous linguistic systems, with their functionality and internal logic. Using L2 categories to describe such systems entails a 'comparative fallacy' [27]. These concerns led Pienemann to propose the notion of 'factorization' [11] (p. 159), i.e. a decomposition of descriptive categories into minimal factors, so that the different meanings merged in a single morpheme in fusional languages can be analyzed one by one. This way one can more closely reproduce the process whereby learners develop morphological categories in interlanguage, beginning with simple one form / one function relationships which may result in non targetlike structures. The example discussed by Pienemann concerns a learner of L2 Swedish. In this language, - $a$ is used for all plural adjectives, while singular forms may end with $\varnothing$, $a$ or $-t$ depending on gender, definiteness and on whether the adjective is attributive or predicative. This learner might have developed an interlanguage rule, whereby $\varnothing$ applies to all singular and $-a$ to all plural adjectives. By following the simple $\varnothing /-a$ opposition, the learner will produce many 
'wrong' forms, according to the target language rules; however, if other diacritic features such as gender and definiteness are 'factored out' of the analysis, what one sees is the emergence of a clear interlanguage rule, 'use $\varnothing$ for singular and - $a$ for plural'. The question then arises: when is number inflection on adjectives acquired? When one sees this interlanguage rule or when the proper Swedish rule is followed? Processability theory makes predictions about acquisition orders based on Levelts's [28] model of language processing. The main concept is that a new structure can appear in interlanguage only when cognitive procedures needed for producing it can be handled by the learner. For example, in order to inflect an adjective for gender or number the 'Category procedure' is required, i.e. the learner must assign a certain class of words to the category 'Adjective', thereby recognizing that gender and number are relevant diacritic features for this class. In order to prove that the Category procedure is operating one needs to demonstrate that the learner is able to inflect lexemes for at least one of the relevant features, such as gender or number. This may occur long before the learner has been able to deal with the complex array of form-function relationships involved in the L2. Factorization is useful to discover these incipient regularities, so that as soon as one of them is observed, the Category procedure can be said to be acquired, regardless of accuracy according to L2 norms. Furthermore, PT focusses on emergence as "the point in time at which certain skills have, in principle, been attained or at which certain operations can, in principle, be carried out" [11] (p. 138). Hence, the notions of emergence and factorization are fundamentally related to PT's aim to provide a psycholinguistic model of L2 acquisition based on the gradual development of increasingly complex cognitive procedures.

This article, whose aim is not to test PT per se, will build on Pienemann's [11] notion of 'factorization' to analyze the interlanguge development of an Eritrean learner of Italian. The discussion will focus on the acquisition of two verb forms, presente ('present tense') and passato prossimo ('present perfect'). The research questions are:

from a methodological point of view, can L2 structures be broken up in simple form/function relationships before more complex, target-like form/functional combinations are considered?

- do these different operationalizations of what is being acquired lead to different acquisition sequences?

are acquisition sequences found in previous research confirmed with these different operationalizations?

In order to confirm or falsify an acquisition sequence one must not only explicitly define the structures involved, but also the acquisition criteria, which allow us to confirm that structure $\mathrm{A}$ is acquired before structure $\mathrm{B}$. As we have seen, the construct 'acquisition' can be interpreted in many different ways, from the first appearance of one or two tokens to $80-90 \%$ correct use. In this paper we will employ an emergence criterion, which will be explicitly defined in the following sections.

\section{PRESENTE AND PASSATO PROSSIMO IN ITALIAN}

In Italian, presente (henceforth translated as 'present tense') is used to indicate the simultaneity of an action with the moment in which it is expressed. This simultaneity can also be understood rather broadly, as in the expression of regular, habitual actions ( $m$ i alzo sempre alle sette 'I always wake up at seven') or statements with universal validity (l'acqua ghiaccia a zero gradi 'water freezes at zero degrees centigrade'). Very frequently the present tense is used to refer to future events, especially if they are imminent or rather certain (Domani vado al mare 'tomorrow I'm going to the seaside'; A giugno mi sposo 'I'm getting married in June'). As historical present, it can also be used to express past events (Napoleone muore nel 1821 'Napoleon dies in 1821').

Formally, the simple present is unmarked, as there is no specific morpheme to indicate this temporal-aspectual category (one can thus say that this tense is expressed by a zero morph). The verb root can be directly followed by a person suffix, which can be preceded by the insertion of a thematic vowel. Person is marked by six suffixes, three for singular and three for plural, as shown in Table 1. Third-person singular endings differ according to verb inflection classes, so called coniugazioni 'conjugations'. A group of verbs of a smaller inflectional class ('third conjugation') requires the insertion of an additional morph to some persons, although the general suffixal pattern remains unchanged.

Table 1. Verb Conjugation in Italian, Exemplified by the Verb Guardare 'to Look'; V = Verb Stem; TV = Thematic Vowel

\begin{tabular}{|c|c|c|}
\hline $1 \mathrm{sg}$ & $\mathrm{V}-o$ & guard-o \\
$2 \mathrm{sg}$ & $\mathrm{V}-i$ & guard-i \\
$3 \mathrm{sg}$ & $\mathrm{V}-a /-e$ & guard-a \\
$1 \mathrm{pl}$ & $\mathrm{V}-\mathrm{TV}-m o$ & guard-ia-mo \\
$2 \mathrm{pl}$ & V-TV-te & guard-a-te \\
$3 \mathrm{pl}$ & V-TV-no & guard-a-no \\
\hline
\end{tabular}

Passato prossimo (the traditional denomination, henceforth translated as 'present perfect'), also called more appropriately perfetto composto ('composite perfect', [29]) is used to refer to facts that have occurred in a very recent past (ieri ho incontrato Paolo 'yesterday I met Paolo') or to more distant events, whose effects are still lasting (Carlo si è trasferito qui da Roma vent'anni fa 'Carlo moved here from Rome twenty years ago'). In the Italian spoken in Northern Italy the composite perfect is used in virtually all perfective past contexts, except for a few genres such as history or fiction. In informal spoken varieties it can also be applied to future events, to indicate that an action precedes another (quando ho finito, ti telefono 'when I'm finished I'm going to call you').

Formally, it is constructed by an auxiliary agreeing in person and number with the subject, followed by a past participle. The auxiliary is essere 'be' with unaccusative verbs and avere 'have' with the others. In the latter class of verbs the past participle is formed by adding the invariable suffix to to the verb theme (barring a few irregular verbs); with unaccusative verbs and auxiliary $b e$, the participle agrees in gender and number with the subject, thus giving the suffixes $-t o,-t a,-t i$, $-t e$, for masculine.singular, feminine singular, masculine plural and feminine plural, respectively. The par- 
ticiple of transitive verbs also agrees in gender and number with the direct object, when this is a preverbal clitic pronoun (e.g. Io le ho trovate 'I have found them').

\section{PREVIOUS RESEARCH ON THE ACQUISITION OF VERB MORPHOLOGY IN L2 ITALIAN}

Most of the research on the development of the verb system in L2 Italian has been conducted by a team of researchers coordinated by the University of Pavia (a synthesis of this work can be found in [30]). Taking a functionalist perspective, inspired by the European Science Foundation project [31], the way in which learners express temporality has been described, from pre-basic and basic varieties, where just a few lexical means and pragmatic principles are employed, to post-basic varieties, where morphological means gradually develop. Such a morphological development has been synthesized in a sequence repeatedly cited in the literature (e.g. [32-34]). Although conditional and subjunctive don't express temporal but modal notions, they are usually included to give a more complete picture of the development of verbal inflectional morphemes.

presente $>$ (aux) participio passato $>$ imperfetto $>$ futuro $>$ condizionale $>$ congiuntivo

present $>$ (aux) past participle $>$ imperfect $>$ future $>$ conditional $>$ subjunctive

The sequence is based on the observation of a certain number of learners who acquired the various forms of the verb system in an implicational order shown in Table 2.

The table represents a cross-sectional description of the end states reached by eleven learners. Similar results have also been achieved from the longitudinal observation of the same learners and others [36].

The terminology used in the table raises a fundamental problem: is it possible to speak of 'present tense' in an interlanguage, even in the first stages, when only one, two or three forms of such a tense are employed? In other words, when does the 'present tense' emerge as a conjugation paradigm like that of standard Italian - with certain temporalaspectual meanings and reference to persons-numbers - and when do fragments of such a paradigm emerge, which in a basic or pre-basic variety do not even constitute a paradigm, being invariable basic forms or appearing in free variation? And if these forms are overgeneralized to all contexts, including past ones, will it still be possible to speak of the emergence of the 'present tense' or should one rather refer to person marking? The same holds for 'present perfect', which in standard Italian covers a range of temporal-aspectual meanings and is inflected according to a complex set of rules, including auxiliary choice and conjugation and the agreement between subject and past participle. Are the first applications of the -to suffix, with erratic auxiliary use, to be considered the first embryonic forms of 'present perfect' or should this term be employed only when uses largely or totally conform to the standard?

Put this way, the question may appear too drastic and simplistic: it is obvious that one cannot straightforwardly apply categories taken from the target language to an interlanguage. However, every time an implicational order like the one presented in Table $\mathbf{2}$ is compiled, one must clearly define the meaning of the linguistic labels used in the columns' headings.

Researchers before us were obviously aware of the problem. They did in fact show that the 'present' form does not emerge all of a sudden, but rather manifests itself through a series of stages, beginning with a basic form, invariable or in free variation, and that the suffixes for different persons in the paradigm appear gradually and are often linked to certain lexemes [35-37]. This gradual differentiation of verb persons is accompanied by an equally gradual appearance of grammatical morphemes encoding temporal and aspectual meanings, beginning with a simple -to suffix to indicate perfectivity, which is then complexified with the use of auxiliaries and, later on, with subject-participle agreement. Bernini [38]

Table 2. (From [35], also Reproduced in [34], p. 90). Explanation of Symbols in the Original Sources: $+\rightarrow$ the Structure is Present; $+? \rightarrow$ the Structure is Present, but with Significant Usage Problems; $\pm \rightarrow$ the Structure is Present on a Limited Number of Lexical Types; -? $\rightarrow$ Very Few Tokens; $-\rightarrow$ the Structure is Absent

\begin{tabular}{|c|c|c|c|c|c|c|}
\hline & Pres/Inf & (Aux)PP & Imperfect & Future & Conditional & Subjunctive \\
\hline Thughiascin & + & + & - & - & - & - \\
\hline Peter & + & + & $-?$ & - & - & - \\
\hline Markos & + & + & + & $-?$ & - & - \\
\hline Xiao & + & + & + & $-?$ & - & - \\
\hline John & + & + & + & + & \pm & - \\
\hline Antje & + & + & + & + & + & - \\
\hline
\end{tabular}


demonstrates how the category 'present tense' attains its ultimate functional value after a long process in which oppositional relationships emerge with other forms specialized for other tenses and aspects.

Banfi and Bernini [34] (p. 95) in their comprehensive review on the development of the verb system in L2 Italian thus summarize the findings about this gradual and parallel emergence: "As regards morphematic constitution, approaching the target language implies first of all the development of person marking within the verb paradigm of the present tense, beginning with stage 2 , right after the constitution of the first fundamental aspectual opposition." This would lead one to suppose that the first opposition to develop is that between perfective (past), expressed by a past participle, with or without auxiliary, and an unmarked form employed with all other tenses and aspects, roughly coinciding with some form(s) of the present tense or, more rarely, for some lexemes and learners, with the infinitive or the imperative. This initially unanalyzed unmarked form would soon begin to be differentiated to express different persons (the present tense paradigm).

However, some questions remain unanswered. For example, when Banfi and Bernini mention 'person marking', are they referring to the systematic use of all person suffixes or only some? And how many, exactly? And do they count only usages in non past-perfective contexts or in temporalaspectual overextensions of the present tense forms as well? Finally, the definition of criteria for assigning $+,+?,-?, \pm$ and - in Table $\mathbf{2}$ is not entirely explicit: for instance, what do 'significant usage problems' and 'very few tokens' mean? In the following pages we will attempt to give explicit and operational definitions for each of these concepts, demonstrating that different definitions lead to different acquisition orders.

\section{METHODOLOGY}

\section{Defining the Structures}

The quote by Banfi and Bernini above seems to suggest an acquisition sequence like the following:

1) basic, uninflected verb form (coinciding most of the time with some person of the present tense).

2) fundamental aspectual opposition between a form marked for perfectivity (past participle) and an unmarked form for all other aspects.

3) appearance of person marking and inflection of the present tense paradigm (still used to express all nonperfective aspects).

As one can see, 'present tense' appears both before the past participle (probably as unanalyzed forms) and after it (as a paradigm inflected for person-number); the more synthetic version of the sequence, cited earlier, has instead present > (aux) past participle. This seeming contradiction may be explained, on the one hand, by the fact that 'present' and 'past participle' are acquired very closely, perhaps simultaneously; on the other hand, which is what we are going to examine in the following pages, the different points of emergence of the 'present tense' may depend on the way in which such a structure is defined from an acquisitional point of view. In the remainder of this paper, explicit operational definitions of each structure will be given, ranging from a more 'interlinguistic' notion, contemplating the existence of partial and extremely simple paradigms (minimally, one form-function association), to one more oriented towards the target language, with its complex form-function relationships. Such definitional work is a crucial step in any attempt to empirically test acquisition sequences.

In the definitions proposed below, the 'structures' (i.e. form-function relationships) whose emergence will be observed, will be formulated essentially in terms of target language norms. Regarding functions, for example, those of 'present' and 'past participle / present perfect' in our definition map the same area of grammatical meaning as in Italian. It would of course be possible to track the emergence of other form-functional relationships, for instance the use of -to to indicate perfectivity, regardless of past time reference, as seems to be the case for some learners in the early stages [38, 39]. However, since one particular semanticogrammatical configuration had to be chosen, it was preferable to remain close to that of Italian, for several reasons: ease of definition and the fact that this is what learners orient to and encounter in the input, so that, as a consequence, such a configuration is soon adopted in the interlanguage. The same holds for the forms of the present tense paradigm, which were identified with those of Italian ( $-o$ for $1 . \mathrm{sg},-i$ for $2 . \mathrm{sg},-a /-e$ for $3 . \mathrm{sg}$ etc.): in theory, a learner might well develop a system in which the first person singular is systematically marked by the - $a$ suffix, or even by a suffix not included in the Italian verb paradigm, such as $-u$ or $-e s$. The column 'other suffixes' in the data collection table was specifically conceived for such instances. Although these possibilities were explored and every possible form-function relationship was taken into consideration, in the end the formfunction associations emerging in this interlanguage are essentially those of the target language. In the very first interviews Markos expressed the first-person singular with suffixes other than $-o$, such as $-a$ or the infinitive; however, such association cannot be said to be systematic and productive, for the same suffixes were also used in other contexts and thus seem to be formulas or random applications.

\section{Present Tense}

In Italian the present tense is characterized by a function (referring to events with certain temporal-aspectual features) and a set of forms (verb root + possible thematic vowel + zero morph + person endings). When one calls a verb 'present tense' it is important to specify whether that verb has just the form of the present tense or whether it expresses its function as well. For example, a learner saying ieri mangio riso 'yesterday I eat rice' is using a form of the present paradigm to express an event in the past. Such cases are usually referred to as overextensions of the present tense, to indicate that a form is extended to functional domains that are not its own. If she said instead ora mangio riso 'now I eat rice', she would be using a form of the present tense to indicate a contemporary event, thus with the same temporal value of the present tense in Italian (one might call it a 'correct use' of the present tense). In both cases, assuming that the speaker is referring to herself, the suffix - $o$ corresponds to the form the verb takes in Italian when inflected for first-person singular. However, in sentences like ieri mangia riso 'yesterday I eats rice' or ora mangia riso 'now I eats rice' overgeneralization 
concerns person marking - in this instance, the third person singular form is overextended to express the first. The first case can be considered an interparadigmatic overextension (forms of one paradigm, such as the present tense, used to express events normally expressed by other paradigms, such as the past tense), while the second can be called intraparadigmatic overextension (forms being exchanged within the same paradigm) [34] (p. 101).

It is thus important to stress that each form of the present tense paradigm expresses at least two functions, one relating to temporal-aspectual reference, the other to person-number reference - a very common situation in fusional languages. The fact is that in acquisition these different meanings are learned gradually and to a certain extent independently, and the same holds for the different forms of the paradigm. In order to provide an explicit operational definition of 'present tense' within an acquisition sequence, it will thus be necessary to specify what (sets of) forms and functions are being referred to. In this study, we will differentiate between a 'present tense' - as a paradigm expressing different persons with a well-defined temporal meaning - and simple 'person marking', used to indicate person and number regardless of their being applied to present temporal contexts. Furthermore, three different definitions of present tense emergence will be given: a minimalist one, seeing the emergence of present even when just one systematic and productive relationship is established between one form of the paradigm and one array of tense-aspect and person-number meanings; an intermediate one, based on the emergence of a miniparadigm [40] constituted by two persons-number; and a third definition corresponding to that of the target language, with all the persons of the paradigm (or at least those for which there are relevant contexts, provided there are at least four different persons).

Present 1 (PR 1) Function: present time, one personnumber; Form: $\mathrm{V}+\varnothing+$ one ending.

Emergence of PR1: emergence of at least one systematic and productive form-function relationship between a suffix $\mathrm{x} 1$ and a person $\mathrm{y} 1$ in present temporal contexts.

Present 2 (PR 2) Function: present time, two personsnumber; Form: $\mathrm{V}+\emptyset+$ two endings.

Emergence of PR2: emergence of two systematic and productive form-function relationships between two suffixes $\mathrm{x} 1$ and $\mathrm{x} 2$ and their respective persons $\mathrm{y} 1$ and $\mathrm{y} 2$ in present temporal contexts.

Present 3 (PR 3) Function: present time, four or more persons-number; Form: $\mathrm{V}+\varnothing+$ an ending for each personnumber.

Emergence of PR3: emergence of a systematic and productive form-function relationship between all suffixes and all persons in present temporal contexts.

\section{Person Marking}

We have seen that the different forms of the "present tense' paradigm combine two sets of meanings, one regarding tense-aspect values, the other those of person-number. Following Pienemann's [11] notion of factorization, they can be set apart in order to examine how suffixes for expressing various persons are acquired independently from their being used to express present events. From this point of view, interparadigmatic overextensions are factored out, and only the emergence of subject-verb agreement is considered. Once again, one can take a minimalist perspective in which emergence is credited with just one systematic relationship between a suffix and a person-number, or that of miniparadigms of two form-functions, up to the unfolding of the entire paradigm. Three definitions thus follow:

Person marking 1 (PM 1) Function: one personnumber; Form: $\mathrm{V}+\varnothing+$ one ending.

Emergence of PM1: emergence of at least one systematic and productive form-function relationship between a suffix $\mathrm{x} 1$ and a person $\mathrm{y} 1$.

Person marking 2 (PM 2) Function: two personsnumber; Form: $\mathrm{V}+\varnothing+$ two endings.

Emergence of PM2: emergence of two systematic and productive form-function relationships between two suffixes $\mathrm{x} 1$ and $\mathrm{x} 2$ and their respective persons $\mathrm{y} 1$ and $\mathrm{y} 2$.

Person marking 3 (PM 3) Function: four or more persons-number; Form: $\mathrm{V}+\varnothing+$ an ending for each personnumber.

Emergence of PM3: emergence of a systematic and productive form-function relationship between all suffixes and all persons.

\section{Past Participle / Present Perfect}

Just as it is possible to give different definitions of "present tense' - which may have consequences on its appearing before or after the 'past participle' in a developmental sequence - 'past participle' too can be defined in several ways. One can see it as a straightforward form, typical of the first stages of interlanguage, consisting of the suffix -to simply added to the verb stem. The suffix can also be $-t a,-t i$, $-t e$, reflecting a possibility existing in the input. However, for our purposes we will factor out gender and number agreement, treating such suffixes as allomorphs. All these cases will be labeled 'past participle', summing usages with and without an auxiliary verb. What is being observed is the emergence of an association between -to and perfective past and in this first sense the auxiliary's presence is also factored out of the analysis.

The term 'present perfect' can instead be used for the complex structure aux $+\mathrm{V}$-to [39] (p. 31). It is true that in order to form a correct passato prossimo in Italian further requirements need to be met, including auxiliary choice, its conjugation and possibly past participle agreement. These factors too will not be taken into consideration and any use of the past participle together with an auxiliary verb will be counted as a correct instance of 'present perfect'. 1

As regards functional application, only those uses of the past participle and the present perfect whose tense-aspect configuration corresponds to the Italian present perfect (in the Northern variety the learner is exposed to) will be considered correct, that is, those marking perfective past events.

\footnotetext{
${ }^{1}$ A third possibility actually exists - which does not appear in standard acquisition sequences but is discussed in the literature and can be found in the data - where a verb is preceded by an auxiliary but is not followed by a past participle suffix, as in io ho mangio 'I have eat'. However, these constructions are not very frequent and their interpretation would require a complex discussion which is beyond the scope of this paper.
} 
The following two formulations are thus provided:

Past participle (PP 1) Function: past perfective event; Form: $\mathrm{V}+-t o,-t a,-t i,-t e$.

Emergence of PP1: emergence of a systematic and productive relationship between the suffixes $-t o,-t a,-t i$, -te and the expression of past perfective events.

Present perfect (PP 2) Function: past perfective event; Form: aux + V + -to, -ta, -ti, -te.

Emergence of PP2: emergence of a systematic and productive relationship between the use of aux $+\mathrm{V}+-t o,-t a,-t i$, -te and the expression of past perfective events.

\section{DATA}

The learner we will be focusing on is Markos, a young Eritrean aged 20 whose first language is Tigrinya; he also had some schooling in English. Recordings took place between 1986 and 1987 in a project coordinated by the University of Pavia, whose transcriptions have been subsequently edited and published by Andorno [41]. Markos was first interviewed one month after his arrival in Italy. Eleven more interviews were recorded in the following seven months and it is possible to follow his interlanguage from a very basic variety to a post-basic system with rather complex inflectional morphology. Only the first six interviews will be considered in this paper, as both structures investigated emerged in this time spam. Interviews lasted between 18 and 40 minutes, adding up to a total of 176 minutes Most of the learning took place spontaneously, although Markos also attended some Italian classes. This explicit teaching occasionally surfaces during the interviews, when he comments on some new rules learned at school.

Interviews were semi-structured and touched upon various conversation topics, including the migratory experience, daily life in Italy, Eritrea's history, politics, culture and society, opinions about events and people, comments on L2 Italian and the Italian sociolinguistic situation. More structured communicative activities were also proposed, including some film and picture-story retellings, describing pictures, formulating hypotheses based on stimulus materials, expressing future projects and plans.

Markos' interlanguage has been analyzed in a number of previous studies (see [41] for a complete bibliography). The most relevant study for our work is Bernini [36], entirely devoted to the emergence of verb paradigms.

\section{Constructing Distributional Tables}

Based on the transcriptions, items to be analyzed are inserted in distributional tables, in which form-function associations are represented (see example in Appendix A; all distributional tables and analyses are available at www.gabrielepallotti.it). As regards the present tense, the table includes six columns for the Italian verb endings, plus another column for other forms, and six lines for each person of the paradigm, plus one for dubious cases in which person reference is not clear. The table reports all verb forms produced with clear reference to the area of temporal meanings covered by the present tense in Italian. The verb form is quoted together with its subject, when this is produced. Each cell reports the total number of types and tokens produced and whether they are correct or not according to the interlan- guage rule. The morphemes $-a$ and $-e$ of third-person singular are considered allomorphs and are thus summed together. A separate table reports the number of cases in which the present form is clearly missing, given the temporal frame, so that the number of omissions can be calculated as well.

Other tables are compiled for past participle and present perfect, in which 'correct' uses (according to explicitly defined interlanguage rules), omissions and overextensions are recorded.

\section{Items Excluded from Analysis}

Items that are not taken into consideration in the analysis are echoes (defined as tokens repeating a form produced by the interviewer in the 50 preceding words), tokens with unclear form or meaning, those cited when reporting metalinguistic activities declaredly learned in class. Probably formulaic verb forms, or those belonging to very irregular paradigms, are also ruled out, including the existentials $c^{\prime} \grave{e}$ 'there is' and $\mathrm{ci}$ sono 'there are', the entire conjugation of the verb essere 'be', the verb avere 'have' used as an auxiliary and a few other possible formulas (an exhaustive list is provided in Appendix B). However, all productions considered as possible formulas are analysed if they are productively inflected in previous parts of the interview. All these exclusions are made visible in the distributional tables, where items are simply crossed out.

\section{Emergence Criterion}

In this article acquisition orders will be based on the notion of emergence, defined as 'the first systematic and productive use of a structure' [25] (p. 366). The terms themselves appearing in the definition need to be clearly defined (for a broader discussion see [25]). By 'linguistic structure', at least in inflectional morphology, we mean an association between a phonological form and a grammatical function [42]. 'Use' refers to the ability to produce the structure orally in a spontaneous and unplanned way. Use is said to be 'productive' when there is evidence that it is not exclusively formulaic, mnemonic, which can be demonstrated when there are creative constructions or a sufficient lexical variety in the morpheme's application. Finally, use can be defined 'systematic' if it appears to be targeted, selected, which can be demonstrated through statistical tests of independence of distributions. We are now going to illustrate the operational procedures through which the emergence criterion was applied to data, taking as an example the structure 'use of suffix $-o$ to express 1.sg present tense'.

Robustness In order to draw reliable conclusions about the emergence or non-emergence of a structure, a minimum of four contexts is required. ${ }^{2}$ If this threshold is not reached, data will simply be considered to be insufficient.

Productive use The emergence criterion's definition includes a productivity requirement. This can be demonstrated in various ways:

Morphological minimal pairs: different grammatical morphemes on the same lexeme, correctly inflected for per-

\footnotetext{
${ }^{2}$ The threshold of four obligatory contexts has been chosen as an intermediate, though rather conservative, option among those used in previous research, which ranged from one [24] to three [3, 44], four [8, 11: p. 145, 16] and five [11: p. 124, 22].
} 
son and number (Maria mangia/io mangio 'Maria eats / I eat').

Creative constructions: for instance io bugio, where the suffix $-O$ is correctly applied to form a 1.sg present tense, but the verb does not exist in Italian. In fact, in Italian bugia means the noun 'lie', but there is no verb 'to lie', which is expressed by dire bugie 'to tell lies'.

Lexical and grammatical variety: the morpheme alternates with other morphemes on different lexical stems, all appropriately inflected (e.g. lui scrive/andiamo 'he writes/we go')

To conclude that a structure is used productively, two morphological minimal pairs must be present, each of which can be substituted by one creative construction or three unmatched pairs of lexemes.

Systematic use The emergence criterion includes a systematicity requirement as well. It is in fact possible for a structure to be used frequently and productively, but in an unsystematic, casual way, in free variation, without a clear functional value. In order to evaluate the chance of a distribution a statistical test like Chi-square is applied to token counts, which is replaced by Fisher exact test when expected frequencies are smaller than 5 [43] (p. 265). A 2x2 matrix is constructed for each form-function relationship (Table $\mathbf{3}$ ).

Table 3. Interview 1, Use of -0 to Indicate 1.sg. Fisher Exact Test, $\mathbf{p}=0.54$

\begin{tabular}{|c|c|c|c|}
\hline & $\boldsymbol{- o}$ & Not $\boldsymbol{- o}$ & Total \\
\hline \hline $1 . \mathrm{sg}$ & 2 & 9 & 11 \\
\hline Not 1.sg & 0 & 5 & 5 \\
\hline Total & 2 & 14 & 16 \\
\hline
\end{tabular}

One can see that in this interview Markos uses the -o suffix twice to indicate the first person singular of the present tense, but this is omitted in nine other cases. It is never overextended to express persons other than first singular. An incipient systematicity of application can thus be noted, but frequencies are still so low that the same distribution might have occurred by chance. Thus, one cannot conclude that in this interview the suffix is produced with enough systematicity to establish emergence.

\section{FINDINGS}

\section{Emergence of Present Tense}

The first interview contains 11 contexts for present tense first-person singular. Markos uses the - $o$ suffix only twice; in another two instances he overuses the third person suffix - $a$ while in the remaining seven cases the verb appears as an infinitive. Usage thus appears to be hardly systematic. Some evidence for productivity can be found in the morphological minimal pair io so / tu sai 'I know / you know', but on the whole the morpheme is applied to too few lexemes to be able to reach any firm conclusion. As regards third-person singular, it is expressed twice with the $-a$ suffix and once with an overextension of 2.sg vuoi '(you) want'. However, the - $a$ ending appears only on the lexeme parla '(he) speaks' and it is also overgeneralized to 1.sg and 3.pl contexts, so that one cannot conclude that its use is systematic. $(p>0.1)$ and productive.

The second interview offers fewer contexts for using the first-person singular, but application of - $o$ looks more systematic, occurring in 6 out of 7 cases. The same holds for $a /-e$ for $3 . s g$, correctly used 4 times out of 7 and never overextended to other persons. There is enough evidence for recognizing the emergence of a systematic and productive association between $-o$ and 1.sg marking: the distribution of the form is targeted $(p<0.05)$ and productive (two morphological minimal pairs, io apro / tu apri 'I open / you open'; io lavoro / mia madre lavora 'I work / my mother works'). The distribution appears to be systematic for 3.sg as well ( $p<$ $0.05)$. There is also evidence for productive use - the same morphological minimal pair - io lavoro / mia madre lavora 'I work / my mother works' and the - $a$ morpheme being applied to two more lexemes (fischia, parla 'whistles, speaks'). However, the emergence criterion requires, besides the morphological minimal pair, the application of at least three different morphemes and this is why the $(+)$ value will be scored, to indicate that almost all conditions in the criterion are met. In this second interview one can thus conclude that the first sense of 'present' has emerged, that is, a systematic and productive relationship between one form $(-o)$ and one function (1.sg). Although almost all requirements are satisfied, one cannot conclude that the second sense of present has emerged, which is characterized by mini-paradigms where two forms and functions are systematically related.

In the third interview, too, the use of - $o$ for 1.sg appears consistent: the suffix is used in 12 out of 14 contexts and it is never overgeneralized to other persons $(p<0.05)$. There is also evidence for productivity, but slightly below the level required by the emergence criterion, hence the $(+)$ in the table. The picture for third-person singular presents is different, with the - $a$ suffix being correctly applied in the only obligatory context, although this is still the same lexeme parla 'speaks'. However, the same suffix is often overgeneralized to other persons, such as 1.sg and 3.pl, so that its use cannot be said to be systematic.

From the fourth interview onwards, the use of 1.sg and 3.sg suffixes appears definitely more stable and, while some omissions and overextensions remain, the emergence criterion is always satisfied. In this interview the suffix $-i$ for $2 . \mathrm{sg}$ also emerges. Although the contexts are only 6 , the suffix is applied consistently in 5 of them, with sufficient lexical variety to be able to conclude that it is also productive.

The fifth and sixth interviews provide contexts for 1.pl and 3.pl as well, which are formed by systematically and productively applying the relevant morphemes.

One can thus conclude that a first minimal sense of 'present tense' emerges in the second interview, where the - $o$ suffix is associated with 1.sg in present temporal contexts. The second sense of 'present tense', with the appearance of two-person mini-paradigms, can be seen as emerging, strictly speaking, only in the fourth interview, although in the second the criterion is almost satisfied. The third sense of 'present tense', involving the entire paradigm, emerges only after the fifth interview. Table $\mathbf{4}$ summarizes these results; symbols are to be interpreted as follows: 
Table 4. Emergence of 'Present Tense' (Person-Number Inflection APPLIED to Present Temporal Contexts)

\begin{tabular}{|c|c|c|c|c|c|c|}
\hline & INT 1 & INT 2 & INT 3 & INT 4 & INT 5 & INT 6 \\
\hline $1 \mathrm{ps} \mathrm{PI} \rightarrow \mathrm{o}$ & - & + & $(+)$ & + & + & + \\
\hline $3 \mathrm{ps} \mathrm{PI} \rightarrow \mathrm{a} / \mathrm{e}$ & - & $(+)$ & - & + & + & + \\
\hline $1 \mathrm{pl} \mathrm{PI} \rightarrow \mathrm{mo}$ & I & I & I & I & + & + \\
\hline $3 \mathrm{pl} \mathrm{PI} \rightarrow$ no & I & I & - & I & + & + \\
\hline
\end{tabular}

$+\quad=$ emergence criterion satisfied

$(+)=$ emergence criterion almost completely satisfied $^{3}$

- $\quad=$ emergence criterion not satisfied

/ = less than 4 contexts

\section{Emergence of Person Marking}

The previous section discussed the emergence of 'present tense', as a paradigm of verb forms expressing both a temporal value (present) and different persons. The same data can be analyzed by ignoring the temporal factor and focussing only on the emergence of person marking. Results shown in Table $\mathbf{5}$ are almost identical to those reported above, as in many cases the use of the present tense paradigm was actu-

\section{Emergence of Past Participle}

The first interview contains 4 contexts for perfective past and the verb takes the -to suffix in three of them. However, two are tokens of the lexeme morto 'dead', which could also be considered an adjective and is excluded from quantitative analyses by Bernini [36] (p. 90). Although the distribution looks rather systematic, with no overextensions, it is not possible to positively conclude that the structure is productively used at this stage.

The second interview also contains two tokens of morto, plus one of finita 'finished', which can also be seen as an adjective or a fixed formula indicating story completion, in the utterance eh, la storia finita qua 'uh, the story [is] finished here'. The only verb that really looks inflected to ex-

Table 5. Emergence of Person Marking (Person-Number Inflection Applied to any Temporal Context)

\begin{tabular}{|c|c|c|c|c|c|c|}
\hline & INT 1 & INT 2 & INT 3 & INT 4 & INT 5 & INT 6 \\
\hline $3 \mathrm{ps} \rightarrow \mathrm{a} / \mathrm{e}$ & - & $(+)$ & - & + & + & + \\
\hline $1 \mathrm{pl} \rightarrow \mathrm{mo}$ & I & I & + & I & + & + \\
\hline $3 \mathrm{pl} \rightarrow$ no & I & 1 & - & I & + & + \\
\hline
\end{tabular}

ally associated with present contexts, with few interparadigmatic overextensions. However, an interesting difference can be noticed in the third interview, in which Markos narrates a series of past events in the first person plural of the present tense (andiamo, entriamo, facciamo '(we) go, enter, do'). With respect to person marking, there is enough evidence to conclude that the suffix -amo is used productively and systematically to express 1.pl. Therefore, in the third interview the first mini-paradigm of two forms and functions to indicate 1.sg and 1.pl can be noticed. Finally, as for present tense, the entire paradigm emerges only after the fifth interview, with the exclusion of the second person plural, for which there are too few obligatory contexts. ${ }^{3}$ As regards productivity, this means the presence of just one morphological minimal
pair, or one creative construction, or 3-5 different lexemes inflected with the morpheme. As regards systematicity, the $p$ value is between 0.05 and 0.10 . press perfective past is andare 'go', in forms like andato, andata, andate 'gone-sg-m', 'gone-sg-f', 'gone-pl-f', with six tokens altogether. However, lexical and formal variety is still too limited to satisfy the emergence criterion.

In the third interview the past participle is produced only twice out of 16 contexts requiring a perfective past. Even though there are no overextensions, the suppliance rate is too low for the distribution to be statistically significant, nor for being able to assert that use is productive.

Past participle emerges in the fourth interview, where it is applied to 6 out of the 9 obligatory contexts, with just one overextension of fatto 'done' to refer to a present event. The suffix -to can also be said to be productive, being applied to three different lexemes, two of which also appear with other endings (entrato 'entered' alternates with entra 'enters' and andata 'gone-sg-f' with va 'goes'). 
Table 6. Emergence of Past Participle (V-to/ta/ti/te, with or without Auxiliary)

\begin{tabular}{|c|c|c|c|c|c|c|}
\hline V+to & INT 1 & INT 2 & INT 3 & INT 4 & INT 5 & INT 6 \\
\hline \hline $\mathrm{V}+\mathrm{to} / \mathrm{a} / \mathrm{i} / \mathrm{e}$ & - & - & - & + & + \\
\hline
\end{tabular}

The structure's emergence is confirmed in subsequent interviews, although it should be noted that suppliance rate is still very low in the fifth sample, in which in only 5 out of 33 past perfective contexts is the verb inflected with the suffix to $(15 \%)$, while all the others are marked with a present form. However, there are no overextensions, which legitimates the conclusion that use of -to to express past perfectivity - though far from being automatized and consistent - is already systematic, targeted and this is sufficient to meet the emergence criterion's requirements. This concerns, by definition, the first systematic and productive uses - a different criterion, requiring, for example, 60 or $80 \%$ correct uses, would not have been satisfied. In the sixth interview, one month later, a considerable consolidation is demonstrated, with 56 out of 68 past perfective contexts appearing with the -to suffix, an application rate of $82 \%$ (Table 6 ).

\section{Emergence of Present Perfect}

The passato prossimo 'present perfect', defined as the systematic use of the form aux $+\mathrm{V}$-to to express perfective past, is the last form to emerge (Table 7). Only sporadic uses are observed in the first interviews: in addition to the previously mentioned ha morto 'has died / is dead' in the first two samples, one also finds ha visto 'has seen' in the third and the fourth one. The structure is applied to two different lexemes in the fifth interview, ho comprato '(I) have bought', ha fatto '(he) has done', but data are too scant to meet the emergence criterion's standards of systematicity and productivity. This happens only in the sixth interview, when the structure soars to 43 tokens on 25 different lexical types. There are still 13 past participles with no auxiliary and 12 cases in which past perfective events are expressed by verbs in the present tense. However, it is very clear that at this point a systematic and productive association has emerged between the form aux $+\mathrm{V}$-to and the past perfective meaning. It should be recalled that here we are dealing with the appearance of the interlanguage rule aux $+\mathrm{V}$-to, factoring out auxiliary choice (e.g. in siamo parlato 'we are talked' or siamo cominciato 'we are begun') or subject-participle agreement (as in noi siamo uscito 'we have gone out', which in Italian should be noi siamo usciti). Although these sentences are ungrammatical according to target language norms, they were scored as correct uses of the interlanguage structure aux $+\mathrm{V}-t o$.

\section{DISCUSSION OF FINDINGS: A RE-ANALYSIS OF THE ACQUISITION SEQUENCE}

Table 8 summarizes results by presenting a global picture of the emergence of various structures in their different definitions. In the first interview none of the structures being examined has emerged. In the second interview the first systematic and productive association between a suffix $(-o)$ and a person (first singular) can be discerned. This association holds in present contexts, so that one can conclude that both person inflection (Person marking 1) and person and present tense inflection (Present tense 1) have been acquired at this time. The first mini-paradigm appears in the third interview, when two suffixes ( $-o$ and -amo) are systematically used to express two different persons (1.sg and 1.pl, respectively) (emergence of Person marking 2). However, in this interview the suffix -amo is indeed used to mark first person plural, but not exclusively present tense, since it is overextended to past contexts as well. Only in the fourth interview does one find a mini-paradigm in which different endings are systematically employed to indicate both different persons and present tense (emergence of Present 2). In this interview the Past participle, too, is used systematically, that is, the suffix -to (and its allomorphs $-t a,-t e,-t i$ ) is consistently associated with perfective past events. In the fifth interview the present tense paradigm is fully deployed, both in all temporal contexts (Person marking 3) and for person marking and present tense reference (Present tense 3). Finally, in the sixth interview the form aux $+\mathrm{V}$-to begins to be systematically used to express perfective past (emergence of Present perfect).

Based on this synthesis, let us return to the original research questions. Is the sequence 'present tense > (aux) past participle' confirmed? And does this hold also for the more fine-grained sequence reconstructed from Banfi \& Bernini's

Table 7. Emergence of Present Perfect (aux + V-to/ta/ti/te)

\begin{tabular}{|c|c|c|c|c|c|c|}
\hline AUX + V +to & INT 1 & INT 2 & INT 3 & INT 4 & INT 5 & INT 6 \\
\hline \hline Aux $+\mathrm{V}+$ to & - & - & - & - & - \\
\hline
\end{tabular}

Table 8. Summary of Findings

\begin{tabular}{|c|c|c|c|c|c|}
\hline INT 1 & INT 2 & INT 3 & INT 4 & INT 5 & INT 6 \\
\hline \hline \multirow{3}{*}{} & PR1 & & PR2 & PR3 & \\
& PM1 & PM2 & & PM3 & \\
& & & PP1 & & PP2 \\
\hline
\end{tabular}


[34] quote, namely 'unmarked form/present > form marked for perfectivity > person marking'?

Assuming a minimalist perspective - recognizing the partial and simple nature of form-function relationships in interlanguage, so that, for example, person marking can be said to emerge when at least one systematic relationship is observed between an ending and a person - Markos' data produce the following sequence:

Present tense 1, Person marking 1> Past participle > Present perfect

If an intermediate perspective is adopted instead (e.g. the one followed by Kilani-Schoch \& Dressler [40] for the L1) which sees rules as having emerged only when a miniparadigm of two forms and two functions is created - the conclusion will be that:

Person marking $2>$ Present tense 2, Past participle > Present perfect

Finally, by taking the target language perspective, so that a structure is seen to emerge only when it is manifested through the entire paradigm, the sequence will look like:

Past participle $>$ Person marking 3, Present tense $3>$ Present perfect

These conclusions can be compared to the acquisition sequences for L2 Italian suggested by Berretta [35], Giacalone Ramat [32], Banfi and Bernini [34] and others. Such sequences are confirmed in two out of three of the interpretations. Only the third case would seem to be contradictory, with the past participle preceding the present tense. However, it is unlikely that researchers who spoke of 'present tense' as the first form had in mind the development of the entire conjugation paradigm. This last sequence seems, however, to be compatible with Bernini's [38] view, according to which the first productive morphological endings are those of the past participle, following a period of basic forms which may well come from the present tense paradigm, but are not yet productively inflected. Secondly, it should be borne in mind that our analysis rests on a particular definition of the emergence criterion - different definitions may lead to slightly different results. Peloso [45] has, in fact, compared the criterion followed here with others, notably those proposed by Di Biase and Kawaguchi [18] and Zhang $[16]^{4}$. The three criteria produce basically the same results in the majority of cases, with some noteworthy exceptions. For instance, by following the criterion proposed by Zhang [16], a rather generous one, one might say that the past participle has already emerged by the second interview, when a certain number of tokens is produced on a sufficiently varied set of lexemes. Furthermore, Present tense 2 (a mini-paradigm with two forms and functions) emerges already in the second interview according to Zhang's [16] and Di Biase and Kawaguchi's [18] criteria, while the criterion followed here, a rather demanding one, falls slightly short of being satisfied. These differences appear even when three criteria are all targeted at identifying the point of emergence. Much larger

\footnotetext{
${ }^{4}$ The criteria are 'the adjective suffix -de (ADJ) was viewed as having emerged if there were a minimum of four tokens of it in a sample set. In addition, the context in which de (ADJ) occurred had to vary lexically in at least two of the four tokens' [16] (p. 451) and 'the rule is supplied more than once in lexically and structurally varied environments' [18] (p. 290).
}

differences would be found with very different acquisition criteria, such as those requiring mastery up to 60 or $80 \%$ of correct uses. Finally, our analysis was based on just one learner, whereas previous sequences were compiled after observing several individuals, both longitudinally and crosssectionally. More studies are needed to test whether the sequences found for Markos are confirmed by data from other subjects.

To conclude, we wish to restate that our main aim here was methodological: we wanted to show that every falsifiable acquisition sequence should be grounded on explicit operational definitions both of acquisition criteria and of the linguistic categories involved in the sequence, and that differences in operational definitions may lead to different acquisition orders.

\section{CONCLUSIONS AND IMPLICATIONS}

In this article we have demonstrated how important it is, for acquisitional research, to provide explicit definitions of the constructs being used. In order to state that a structure A is acquired before a structure B, not only does one need to operationally define what is meant by 'acquisition', but one also needs to operationally define what is meant by 'structure A' and 'structure B'. The use of metalinguistic terms taken from the target language can be misleading, for it tends to obscure the fact that many such 'structures' are not simple, but result from complex form/functional relationships forming rich paradigms, which emerge gradually in the interlanguage. It is these more elementary relationships that need to be observed and followed one by one, if a more accurate developmental picture is to be provided. Nothing prevents one from describing the emergence and consolidation of more complex form/function aggregates, up to those entirely conforming to L2 norms. However, for each definition of 'structure', it will always be necessary to provide clear and explicit identification criteria.

The resulting acquisition orders will thus be relative to the definitions given. In principle, it seems advisable to provide similar definitions of the structures appearing in the same sequence, either treating them all as they are represented in the target language, or applying to all of them definitions reflecting the existence of partial paradigms and form-function relationships. However, one could also relate the emergence of a structure 'as defined according to L2 rules' with the emergence of another structure 'defined in interlanguage terms', stating, for example, that the first partial manifestations of A precede or follow the onset of standard use of B. In any case, it will always be necessary to break up complex structures into 'factors' [11], making explicit what combinations of factors are being referred to. Such a practice, together with a similar explicitness regarding acquisition criteria, would allow researchers to produce more reliable and better falsifiable statements concerning acquisition sequences.

This in turn has clear theoretical implications, as any comparison among theories making predictions about acquisition orders requires that key constructs such as acquisition and the structures being acquired be explicitly defined. The evaluation and comparison of competing theoretical accounts of SLA needs to rest on clear and reliable operational definitions. The present discussion can also have a pedagogical impact, as it stimulates teachers and syllabus designers to 


\section{APPENDIX A}

\section{Sample Distributional Table and Analysis}

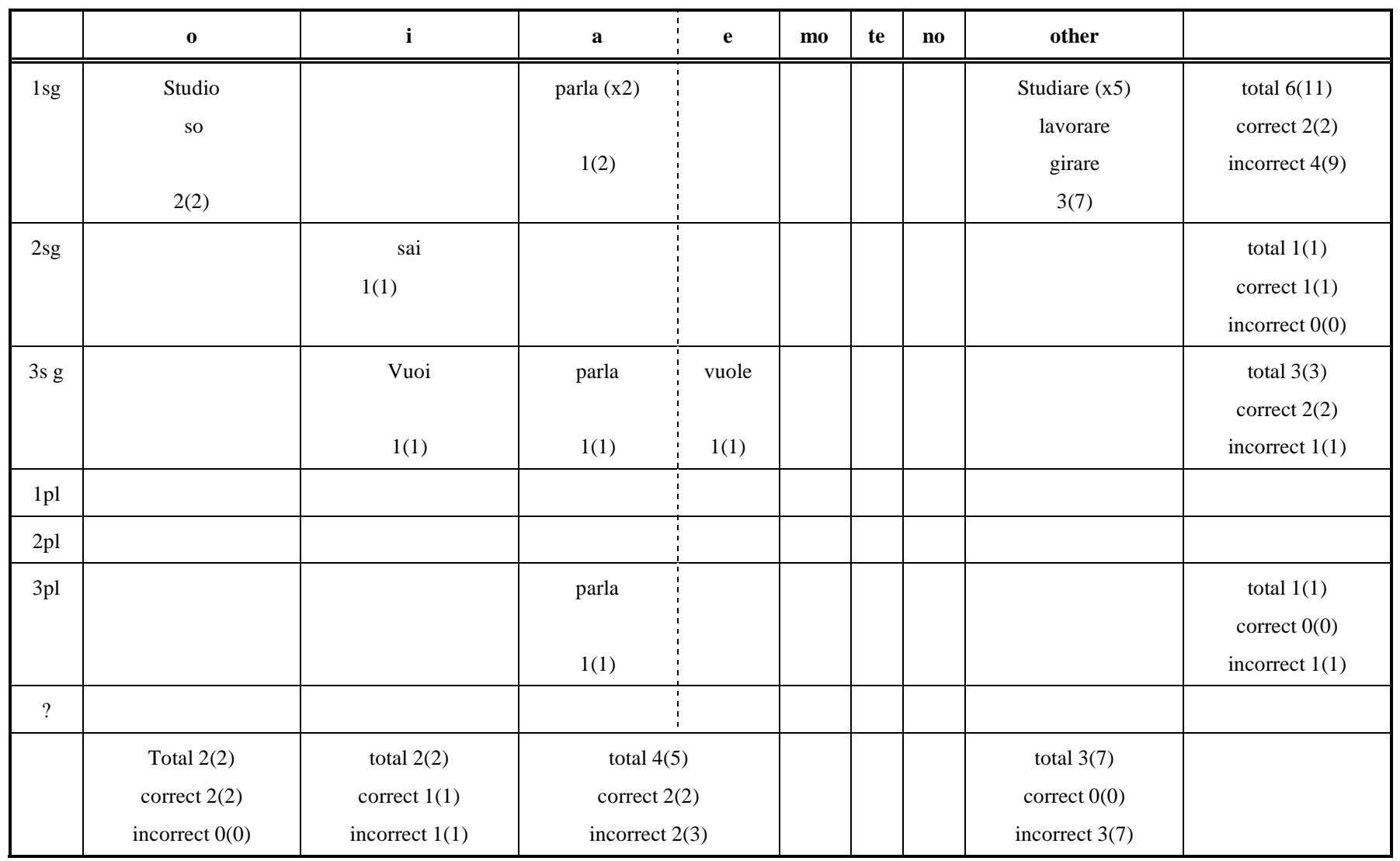

The table above includes all the items analyzed for the emergence of present tense (person marking + reference to present time) in Interview 1. Numbers in parentheses indicate tokens. e.g. 3(7) means 3 types and 7 tokens.

\section{Analysis on Form = -o; function 1.sg}

1 morphological minimal pair so/sai, 1 other pair of lexemes so/studio

\begin{tabular}{|c|c|c|c|}
\hline & $\boldsymbol{- o}$ & Not $-\mathbf{0}$ & Total \\
\hline \hline $1 . \mathrm{sg}$ & 2 & 9 & 11 \\
\hline not $-1 . \mathrm{sg}$ & 0 & 5 & 5 \\
\hline Total & 2 & 14 & 16 \\
\hline
\end{tabular}

Fisher exact test $p=0.54$, not significant

Conclusion: emergence criterion not satisfied (-)

Analysis on Form = - a/e; function = 3.sg

2 pairs of lexemes parla/studio; vuole/so

\begin{tabular}{|c|c|c|c|}
\hline & $-\boldsymbol{a} / \boldsymbol{e}$ & Not $-\boldsymbol{a} / \boldsymbol{e}$ & Total \\
\hline \hline $3 . \mathrm{sg}$ & 2 & 1 & 3 \\
\hline not $-1 . \mathrm{sg}$ & 3 & 10 & 13 \\
\hline Total & 5 & 11 & 16 \\
\hline
\end{tabular}

Fisher exact test $p=0.21$, not significant

Conclusion: emergence criterion not satisfied (-) 


\section{APPENDIX B}

\section{Items Excluded from Quantitative Analysis}

The following items were excluded from quantitative analysis and hence do not contribute to the figures reported in the tables.

- Words with unclear or inaudible ending.

- $\quad$ Words with unclear reference.

- $\quad$ Echoes, defined as words uttered 50 words after interviewer's first mention. If the word was first produced by the informant, it was subsequently counted even in echo contexts. If the informant repeats a word changing its morphological ending, the resulting form is retained. If a word is first uttered by the interviewer, then echoed by subject, and repeated again by the subject within 50 words from first or subsequent mentions, all these are considerd echoes and excluded from analysis. If the word repeated as echo should have been inflected differently (e.g. do you have a dog? yes I have three $\operatorname{dog}$ ), then it is retained. In fact, this constitutes evidence that the learner cannot (at least in this instance) use the inflectional morpheme and is following his/her own interlanguage strategy.

- Immediate identical repetitions of the same word or phrase are counted as just one token (e.g. I went went or I went I $w e n t)$. Self repetitions separated by other linguistic material, even within the same sentence or turn, are counted as multiple tokens.

- $\quad$ Probably formulaic items.. A comprehensive list was compiled and is reported below. If any of these forms occurs together with other forms of the lemma in functional alternation, both are retained. For example, if a learner only uttered si chiama ('it is called'), this verb was not analyzed. If she also uttered, in that interview or in previous ones, si chiamano ('they are called') or mi chiamo ('I am called', i.e. my name is), then all of these tokens were counted.

The following list is not meant to be exhaustive for L2 Italian, as it was compiled based on the data analyzed in the present study. Items may be added or excluded - what is essential is that all of them be explicitly stated.

\begin{tabular}{|c|c|}
\hline Exclusion list for verbs & \\
\hline chiamarsi: mi chiamo, si chiama, ti chiami & to be called: I'm called, it's called, you're called \\
\hline (come) si dice & (how) do you say \\
\hline va bene & all right \\
\hline (mi) piace & I like \\
\hline capire: capito, no capito, capisco, capisci & understand: understood, not undertood, I understand, you understand \\
\hline non so & it depends \\
\hline dipende & look (2.sg imperative) \\
\hline guarda (2.sg imperative) & wait (2.sg imperative) \\
\hline aspetta (2.sg imperative) & \\
\hline
\end{tabular}

reflect on the complexity of the acquisition construct and on how learners may build approximate interlanguage grammars which, despite their not being accurate according to target language norms, exhibit regularities based on functional organization principles.

\section{ACKNOWLEDGMENTS}

We wish to thank Giuliano Bernini and three anonymous reviewers for commenting on an earlier version of this paper. All remaining errors are our own.

\section{REFERENCES}

[1] Cazden CB. The acquisition of noun and verb inflections. Child Dev 1968; 39: 433-48.

[2] Brown R. A First language: The Early Stages. Cambridge, Mass: Harvard University Press 1973.

[3] Dulay H, Burt M. Natural sequences in child second language acquisition. Lang Learn 1974; 24: 37-53.

[4] Ellis R. The Study of Second Language Acquisition. Oxford: Oxford University Press 1994.

[5] Larsen-Freeman D, Long M. An introduction to second language acquisition research. London: Longman 1991.
[6] Wode H. Learning a second language: an integrated view of language acquisition. Tübingen: Narr 1981.

[7] Cancino H, Rosansky E, Schumann J. The acquisition of English negatives and interrogatives by native Spanish speakers. In: Hatch E, Ed. Second Language Acquisition: A Book of Readings, Rowley, Mass: Newbury House 1978.

[8] Clahsen H, Meisel J, Pienemann M. On determining developmental stages in natural second language acquisition. Stud Second Lang Acquisition 1981; 3/2: 109-35.

[9] Bardovi-Harlig K. Tense and Aspect in Second Language Acquisition: Form, Meaning, and Use. Oxford: Blackwell 2000.

[10] Bartning I, Schlyter S. Itinéraires acquisitionnels et stades de développement en français L2. J French Lang Stud 2004; 14: 3: 281-99.

[11] Pienemann M. Language Processing and Second Language Development: Processability Theory. Amsterdam: Benjamins 1998.

[12] Pienemann M. Processability theory. In: Van Patten B, Williams J, Eds. Theories in Second Language Acquisition, Mahwah, NJ: Lawrence Erlbaum 2007.

[13] Pienemann M, Di Biase B, Kawaguchi S. Extending Processability Theory. In: Pienemann M, Ed. Cross-linguistic aspects of Processability Theory, Benjamins: Amsterdam/ New York 2005; pp. 199252.

[14] Pienemann M, Johnston M, Brindley G. Constructing an acquisition-based procedure for second language assessment. Stud Second Lang Acquisition 1988; 10: 217-43. 
[15] Pienemann M, Håkansson G. A unified approach toward the development of Swedish as L2: A processability account. Stud Second Lang Acquisition 1999; 21: 383-420.

[16] Zhang Y. Processing constraints, categorial analysis, and the second language acquisition of the Chinese adjective suffix -de (ADJ). Lang Learn 2004; 54: 437-68.

[17] Bettoni C, Di Biase B, Nuzzo E. In press. Postverbal subject in Italian L2 - A Processability Theory approach. In: Keatinge D, Keßler J, Eds. Research in Second Language Acquisition: Empirical Evidence Across Languages, Cambridge: Cambridge Scholars Publishing.

[18] Di Biase B, Kawaguchi S. Exploring the typological plausibility of Processability Theory: Language development in Italian second language and Japanese second language. Second Lang Res 2002; 18/3: 272-300.

[19] Goldschneider JM, DeKeyser R. Explaining the "natural order of L2 morpheme acquisition' in English: A meta-analysis of multiple determinants. Lang Learn 2001; 51: 1-50.

[20] Zobl H, Liceras J. Functional categories and acquisition orders. Lang Learn 1994; 44: 159-80.

[21] Vainikka A, Young-Scholten M. Direct access to X'-Theory. Evidence from Korean and Turkish adult learners of German. In: Hoekstra T, Schwartz B, Eds. Language Acquisition Studies in Generative Grammar, Amsterdam: Benjamins 1994.

[22] Andersen R. An implicational model for second language research. Lang Learn 1978; 28: 221-82.

[23] Bahns J. On acquisitional criteria. IRAL 1983; 21: 57-67.

[24] Glahn E, Håkansson G, Hammarberg B, Holmen A, Hvenekilde A, Lund K. Processability in Scandinavian second language acquisition. Stud Second Lang Acquisition 2001; 23: 389-416.

[25] Pallotti G. An operational definition of the emergence criterion. Appl Linguistics 2007; 28: 361-82.

[26] Hatch E, Faraday H. Research Design and Statistics for Applied Linguistics. Rowley: Newbury House 1982.

[27] Bley-Vroman R. The comparative fallacy in interlanguage studies: The case of systematicity. Lang Learn 1983; 33: 1-17.

[28] Levelt W. Speaking. From intention to articulation. Cambridge, MA: MIT Press 1989.

[29] Bertinetto PM. Il verbo. In: Renzi L, Salvi G, Cardinaletti A, Eds. Grande Grammatica italiana di consultazione Vol II, Bologna: Il Mulino 2001; pp.13-161.

[30] Giacalone Ramat A, Ed. Verso l'italiano: percorsi e strategie di acquisizione. Roma: Carocci 2003.

[31] Perdue C. Adult language acquisition: Cross-linguistic perspectives. Cambridge: Cambridge University Press 1993.
[32] Giacalone Ramat A. Italiano di stranieri. In: Sobrero A, Ed. Introduzione all'italiano contemporaneo Vol. II: la variazione e gli usi, Roma-Bari: Laterza 1993.

[33] Banfi E. Italiano come L2. In: Banfi E, Ed. L'altra Europa linguistica, Firenze: La Nuova Italia 1993.

[34] Banfi E, Bernini G. Il verbo. In: Giacalone Ramat A, Ed. Verso l'italiano: percorsi e strategie di acquisizione, Roma: Carocci 2003; pp. 70-115.

[35] Berretta M. Il futuro in italiano L2. Quaderni del Dipartimento di linguistica e letterature comparate, Università di Bergamo 1990; 6: 147-188.

[36] Bernini G. Lo sviluppo dei paradigmi verbali nelle varietà elementari di apprendimento dell'italiano lingua seconda. In: Bernini G, Giacalone Ramat A, Eds. La temporalità nell'acquisizione di lingue seconde, Milano: Angeli 1990.

[37] Mammoli R. Morfologia verbale in italiano L2. In: Bernini G, Ferrari G, Pavesi M, Eds. Atti del III congresso di studi dell'Associazione Italiana di Linguistica Applicata, Perugia: Guerra 2004.

[38] Bernini G. La seconda volta. La (ri)costituzione di categorie linguistiche nell'acquisizione di L2. In: Costamagna L, Giannini S, Eds. Acquisizione e mutamento di categorie linguistiche, Roma: Il Calamo 2004.

[39] Giacalone Ramat A. Presentazione del progetto di Pavia sull'acquisizione di lingue seconde. Lo sviluppo di strutture temporali. In: Bernini G, Giacalone Ramat A, Eds. La temporalità nell'acquisizione di lingue seconde, Milano: Angeli 1990.

[40] Kilani-Schoch M, Dressler WU. The emergence of inflectional paradigms in two French corpora: An illustration of general problems of pre- and protomorphology. In: Voeikova MD, Dressler WU, Eds. Pre- and Protomorphology, Munchen: Lincom 2002.

[41] Andorno C, Ed. Banca dati di italiano L2. Pavia: University of Pavia, Linguistics Department 2001.

[42] Stankiewicz E. The concept of structure in contemporary linguistics'. In: Waugh L, Rudy S, Eds. New Vistas in Grammar: Invariance and Variation, Amsterdam: Benjamins 1991.

[43] Agresti A, Finlay B. Statistical methods for the social sciences. Upper Saddle River, NJ: Prentice Hall 1997.

[44] Zhang Y. Processing and formal instruction in the L2 acquisition of five Chinese grammatical morphemes. In: Pienemann M, Ed. Cross-Linguistic Aspects of Processability Theory, Amsterdam: Benjamins 2005.

[45] Peloso A. La teoria della processabilità: risultati empirici e riflessioni metodologiche. [Unpublished dissertation]. University of Sassari (Italy), 2006.

(C) Pallotti and Peloso; Licensee Bentham Open.

This is an open access article licensed under the terms of the Creative Commons Attribution Non-Commercial License (http://creativecommons.org/licenses/by-nc/3.0/) which permits unrestricted, non-commercial use, distribution and reproduction in any medium, provided the work is properly cited. 